
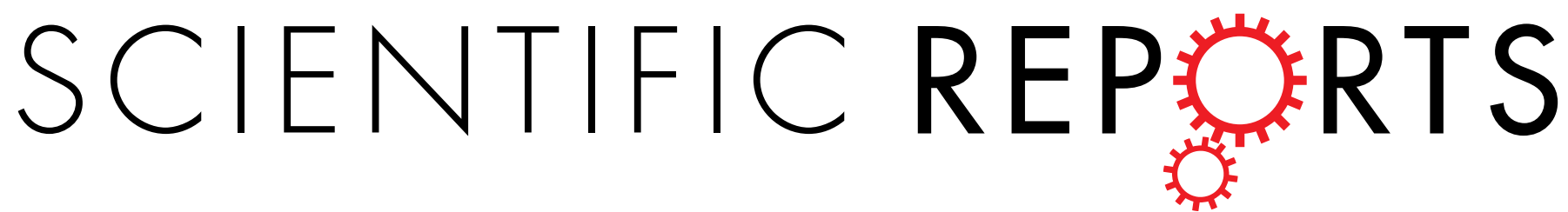

\title{
OPEN Differential expression of the adult specifier E93 in the strepsipteran Xenos vesparum Rossi suggests a role in female neoteny
}

Received: 20 June 2018
Accepted: 10 September 2018

Published online: 21 September 2018

\author{
S. Chafino ${ }^{1}$, D. López-Escardó ${ }^{1}$, G. Benelli ${ }^{3}$, H. Kovac $^{4}$, E. Casacuberta ${ }^{1}$, X. Franch-Marro ${ }^{1}$, \\ J. Kathirithamby ${ }^{2} \&$ D. Martín ${ }^{1}$
}

Holometaboly is a key evolutionary innovation that has facilitated the spectacular radiation of insects. Despite the undeniable advantage of complete metamorphosis, the female of some holometabolous species have lost the typical holometabolous development through neoteny. In Xenos vesparum Rossi (Strepsiptera: Stylopidae), a derived species of the holometabolous endoparasitic order Strepsiptera, neotenic females reach sexual maturity without the pupal and the imaginal stages, thus retaining their larval morphology (with the exception of the anterior part of the body or cephalothorax), while males undergo normal pupal-based metamorphosis. Expression of the "adult-specifier" E93 factor has been shown to be required for proper metamorphosis in holometabolous insects. Here, we investigated the involvement of E93 in female neoteny by cloning XvE93. Interestingly, while we detected a clear up-regulation of $X v E 93$ expression in pupal and adult stages of males, persistent low levels of $X v E 93$ were detected in $X$. vesparum females. However, a specific up-regulation of $X v E 93$ was observed in the cephalothorax of late $4^{\text {th }}$ female instar larva, which correlates with the occurrence of neotenicspecific features in the anterior part of the female body. Moreover, the same expression dynamic in the cephalothorax and abdomen was also observed for other two critical metamorphic regulators, the anti-metamorphic $X v K r-h 1$ and the pupal specifier $X v B r-C$. The specific up-regulation of $X v E 93$ and $X v B r-C$ in the female cephalothorax seems to be the result of an increase in 20-hydroxyecdysone (20E) signaling in this region for we detected higher expression levels of the $20 \mathrm{E}$-dependent nuclear receptors $X v H R 3$ and $X v E 75$ in the cephalothorax. Overall, our results detect a sex-specific expression pattern of critical metamorphic genes in $X$. vesparum, suggesting that neoteny in Strepsiptera results from the modification of the normal expression of $E 93, B r-C$ and $K r$-h1 genes.

From their origin approximately $400 \mathrm{Mya}^{1,2}$, insects have developed three basic types of metamorphic development: (i) ametaboly (Apterygota), the most primitive type that is characterized by the absence of a morphological transformation between the wingless immature individuals and the adults; (ii) hemimetaboly (Exopterygota), in which the juvenile wingless nymphs resemble miniature adults and metamorphose into winged adults during the last juvenile instar; and (iii) holometaboly (Endopterygota), in which the crawling juvenile larvae undergo a dramatic morphological transformation to form the winged adult through a two-stage metamorphic process bridged by the holometabolous-specific intermediate pupal stage ${ }^{3,4}$. Taking into consideration that holometaboly has facilitated the most spectacular radiation of animals, complete metamorphosis can be considered as one of the key evolutionary innovation in insect evolution ${ }^{5,6}$. And yet, in spite of the clear evolutionary advantages of holometaboly, the female of a number of holometabolan species have lost the typical complete metamorphic transformation.
${ }^{1}$ Institute of Evolutionary Biology (CSIC-Universitat Pompeu Fabra) Passeig Marítim de la Barceloneta 37-49, 08003, Barcelona, Spain. ${ }^{2}$ Department of Zoology, University of Oxford, Oxford, United Kingdom. ${ }^{3}$ Department of Agriculture, Food and Environment, University of Pisa via del Borghetto 80, 56124, Pisa, Italy. ${ }^{4}$ Institut für Biologie, Universitaet Graz, Universitaetsplatz 2, A-8010, Graz, Austria. Correspondence and requests for materials should be addressed to J.K. (email: jeyaraney.kathirithmby@zoo.ox.ac.uk) or D.M. (email: david.martin@ibe.upf-csic.es) 


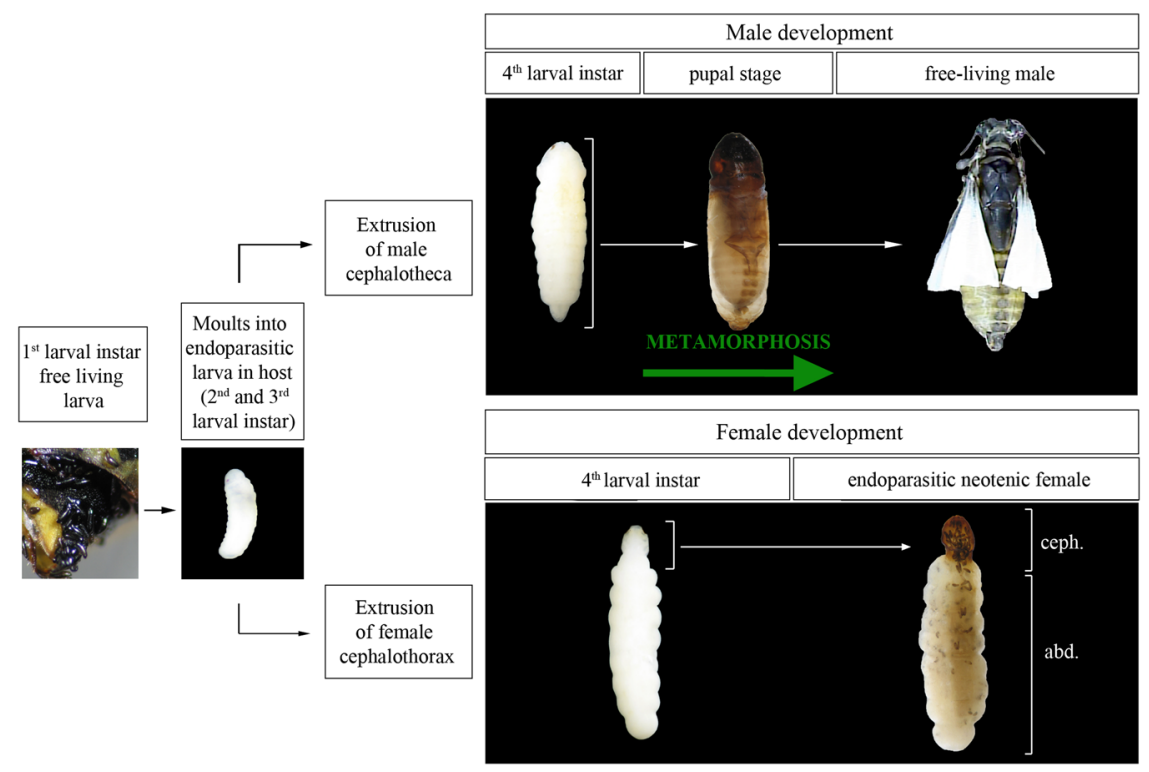

Figure 1. Life cycle of Xenos vesparum. Free living $1^{\text {st }}$ instar planidium enters a wasp nests to parasitize host larva. Upon entering the host, the planidium molts to an apodous endoparasitic $2^{\text {nd }}$ instar larva, which successively molts two additional times. The male $4^{\text {th }}$ instar larva undergoes metamorphosis through pupation (green arrow), and after, it extrudes through the abdomen of the wasp cuticle. The apolised cuticles of the larval instars form the puparium. The free-living male emerges from the puparium as a winged adult. In contrast, the $4^{\text {th }}$ instar female larva does not undergo the pupal-based metamorphic transformation but develops a cephalothorax, which is extruded through the host. The cephalothorax contains adult-specific structures that facilitate the neotenic female in insemination and the release of the planidium, and also contains glands that release pheromones to attract the male. The abdomen (abd.) and the cephalothorax (ceph.) regions in the neotenic female are marked.

The loss of complete metamorphosis in holometabolous insects is exclusively found in females and results from the disappearance of pupal and post-metamorphic stages, a process named paedomorphosis. One particular strategy leading to paedomorphosis is neoteny, where the larval morphology is retained and sexual maturity is attained without a pupal or an imaginal stage $\mathrm{e}^{7,8}$. Interestingly, whereas holometaboly originated only once in insect evolution from ancestors exhibiting hemimetabolous development ${ }^{2}$, neoteny in holometabolous insects has occurred independently several occasions in the beetle superfamily Elateroidea ${ }^{9,10}$ and once in derived lineages of the endoparasitic order Strepsiptera ${ }^{11-13}$. Despite the interest in how insect neoteny has evolved, the molecular mechanisms underlying the loss of complete metamorphosis in holometabolous neotenic females, however, remain poorly understood.

Strepsiptera are a small, bizarre holometabolous order of obligate entomophagous endoparasitoids with extreme sexual dimorphism ${ }^{11-15}$. Males and females of the early branching order of Strepsiptera, the Mengenillidae, emerge to pupate externally from the host. In contrast, males of the families of the derived suborder Stylopidia pupate endoparasitically in the host and emerge as free-living adults, while females remain obligate endoparasites in the host and are neotenic. The neotenic female Stylopidia, such as Xenos vesparum Rossi, produces $1^{\text {st }}$ instar larvae (planidia) which have rudimentary eyes, thoracic limbs, sclerotized cuticle, and are dedicated to host-seeking. Upon finding and entering a host, the planidium molts to a soft cuticle-apodous endoparasitic $2^{\text {on }}$ instar larva. After three consecutive endoparasitic stages where no ecdysis occurs, the male larva extrudes the head (cephalotheca) through the host cuticle and continues the typical holometabolous development whereby it undergoes complete metamorphosis through pupation. At the end of pupation, the male emerges from the endoparasitic puparium as a free-living winged adult. In contrast, the female after the fourth larval instar extrudes the head, thoracic and first abdominal regions (cephalothorax) though the host cuticle and remains endoparasitic in the mobile host. A few days (3-4 days) after extrusion of the cephalothorax, the neotenic female assumes a calling position ${ }^{16}$. During this calling, the female produces a potent pheromone that attracts the male ${ }^{17-19}$. The male then inseminates the female through the brood canal opening in the cephalothorax ${ }^{16}$. After viviparous development in the endoparasitic female, the motile $1^{\text {st }}$ instar planidia emerges through the brood canal opening in the cephalothorax ${ }^{11,13,15}$. Neotenic female Strepsiptera resembles a "bag of eggs" with an extruded cephalothorax without any external adult characteristics, such as antennae, legs and wings, and whose primary function is to be a repository for eggs ${ }^{13,19,20}$ (Fig. 1). Therefore, it could be considered that total endoparasitism in Stylopidia females has led to the simplification of their body plan and represents a state of extreme neoteny. However, it is worth noting that although the abdomen remains larviform, particular structures to aid mating, release of the planidia larvae and the pheromone glands are specifically found in the cephalothorax of neotenic females ${ }^{20}$ (Fig. 1). 
From an endocrine perspective, the metamorphic transition in holometabolous insects is controlled by the sesquiterpenoid juvenile hormone $(\mathrm{JH})$ produced by the corpora allata glands $(\mathrm{CA})^{21-25}$. The presence of $\mathrm{JH}$ during pre-ultimate larval stages prevents premature metamorphosis though the transcriptional induction of the anti-metamorphic transcription factor-encoding gene Krüppel-homolog $1(K r-h 1)^{26,27}$. Conversely, the disappearance of $\mathrm{JH}$ and the down-regulation of $K r-h 1$ at the onset of the last larval instar trigger the metamorphic transformations to the pupal stage by allowing the up-regulation of the transcription factor Broad-complex $(B r-C)$ by the steroid hormone 20 -hydroxyecdysone $(20 \mathrm{E})^{28,29}$. During the final part of the last larval instar, $\mathrm{Br}-\mathrm{C}$ controls the correct switch between larval and pupal forms, thus acting as the "pupal specifier"28-32. In pre-ultimate larval stages, $\mathrm{Kr}$-h1 binds to the promoter region of $\mathrm{Br}-\mathrm{C}$ and inhibits its expression, thus preventing larvae to undergo precocious larval-pupal transformation ${ }^{33}$. Finally, after pupation, a third critical transcription factor, E93, is strongly up-regulated by $20 \mathrm{E}$ and controls the transition from the pupa to the adult, thus acting as the "adult specifier" ${ }^{4}$. During the pupal stage, E93 also represses the expression of $K r-h 1$ and $B r$ - C, thus ensuring the elimination of the two factors whose presence during this period is detrimental for proper adult differentiation ${ }^{1,34}$. Similar to the repressive activity on $B r-C, \mathrm{Kr}-\mathrm{h} 1$ also binds to the promoter region of $E 93$, suppressing its expression before the pupal stage and preventing larvae to undergo precocious larval-adult metamorphosis ${ }^{35}$. Due to their critical importance in the control of metamorphosis in holometabolous and hemimetabolous insects, Kr-h1, $\mathrm{Br}-\mathrm{C}$ and E93 form what we have recently defined as the Metamorphic Gene Network (MGN) ${ }^{1}$.

In order to characterize the genetic control of neoteny in holometabolous insects, a recent pilot study proposed that the appearance of neotenic females in Strepsiptera is linked to the modification of regulatory pathways that underlie pupal determination ${ }^{36}$. The authors identified $\mathrm{XvBr}-\mathrm{C}$ in $\mathrm{X}$. vesparum and found upregulation in males at the larval-pupal transition but not in females. This work suggested that lack of $\mathrm{XvBr}$ - $\mathrm{C}$ upregulation might be one of the reasons underlying the loss of complete metamorphosis in neotenic females. However, it has been shown in T. castaneum that depletion of $T c B r-C$ does not result in the maintenance of larval status but rather to a developmental arrest of the animal at the larval-pupal transition with knockdown animals showing a mix of larval, pupal and adult features ${ }^{1,28-31}$, thus suggesting that additional factors are required to induce complete metamorphosis.

Here, we further investigate the postulated link between the alteration of the pupal determination program controlled by the MGN and the occurrence of adult neotenic X. vesparum females. Due to the critical role of E93 in the formation of the adult form, we have identified X. vesparum E93 homolog (XvE93). Then, we have compared the expression dynamics of $X v E 93$ in males and females during the metamorphic transition. Because the female is composed of a posterior abdomen that is larval-like and an anterior cephalothorax that has features for insemination and release of the $1^{\text {st }}$ instars and the pheromone glands we analyzed the differential expression of XvE93 in these two regions of the female. Moreover, to complete the identification of the factors of the MGN, we have isolated a fragment of the anti-metamorphic $\mathrm{Kr}-\mathrm{h} 1(\mathrm{XvKr}-\mathrm{h} 1)$ factor and have measured its expression levels during the larva-to-adult transition in $X$. vesparum males and females. Finally, to complete the analysis of the MGN in the regulation of neoteny, we have measured the expression levels of $\mathrm{XvBr}$-C in the cephalothorax and the abdomen of $X$. vesparum females. Our results strongly suggest that the low levels of $X v E 93$ expression in $X$. vesparum females underlie the evolution of neotenic development.

\section{Material and Methods}

Strepsiptera collection. X. vesparum specimens used for cloning and gene expression analysis were collected from the following locations:

(i) X. vesparum parasitic in Polistes dominulus were collected in Italy in 2017, in Tuscany (Central Italy) Via Madonna del Piano, 6. Sesto Fiorentino, It-50019, Italy; N4349.064' E1 $1^{\circ} 12.263^{\prime}$ by Helmut Kovac; (ii) X. vesparum parasitic in P. dominulus were collected in 2014, Tuscany (Central Italy) from University of Pisa farm, San Piero a Grado, Pisa $\left(43^{\circ} 40^{\prime} 01.6^{\prime \prime} \mathrm{N} 10^{\circ} 20^{\prime} 21.0^{\prime \prime} \mathrm{E}\right)$ and in a private winery, "La Sughera" farm, Loc. Tonini, Spianate, Altopascio, Lucca $\left(43^{\circ} 48^{\prime} 00.2^{\prime \prime} \mathrm{N} 10^{\circ} 42^{\prime} 02.6^{\prime \prime} \mathrm{E}\right)$ by Giovanni Benelli and J. Kathirithamby; (iii) X. vesparum parasitic in P. dominulus were collected in 2017 in Austria, Gschwendterstraße 76, A-8062 Kumberg, Austria (N47 10.721 E15 34.373) by H. Kovac; (iv) X. vesparum parasitic in P. dominulus were collected from nests in plastic bottles in 2016 in Fauglia, Pisa, by Consolato Latella and J. Kathirithamby. In all cases, specimens were dissected immediately in saline and fast frozen at $-80^{\circ} \mathrm{C}$, or fast frozen and dissected for identification of the endoparasitic stages.

$X$. vesparum transcriptome assembly for sequence analysis. Raw reads were downloaded from NCBI SRA repository with accession numbers SRR1784898 and SRR1784897 which belong to RNA-seq studies on a $X$. vesparum female $4^{\text {th }}$ instar larvae and neotenic females, respectively. Two independent transcriptomes assemblies were carried out with rnaSPAdes ${ }^{37}$ v.0.0.1. Before the assembly, raw reads were trimmed with Trimmomatic ${ }^{38}$ v3.059 using the following options ILLUMINACLIP:/adapters/TruSeq. 3-PE.fa:2:30:10 SLIDINGWINDOW:4:28 MINLEN:50 in order to remove Truseq adapters and low quality reads. Next, by using known E93, Kr-h1, HR3 and E75 protein sequences from Blattella germanica and Drosophila melanogaster, we performed $\mathrm{tBLAST}{ }^{39}$ searches (BLAST v.2.2.31) in order to identify the putative transcripts in X. vesparum and design primers for further experimental confirmation of gene sequences.

Phylogenetic analysis of E93. To understand the phylogenetic relationship of E93 proteins, amino acid sequences from E93 proteins were collected from different insect taxa, including that of $X$. vesparum as well as from two arachnid species as an outgroup (Supplementary Table 1), and aligned using MAFFT ${ }^{40} \mathrm{v}^{2} .299 \mathrm{~b}$ L-INS-I with 1000 iterations. Ambiguously aligned positions were trimmed using trimAl ${ }^{41}$ v14, with the automated 1 algorithm. The best substitution model for phylogenetic inference was selected using IQ-TREE ${ }^{42}$ with the TESTNEW model selection procedure and following the BIC criterion. The LG substitution matrix with 
a 4-categories discrete $\Gamma$ distribution and allowing for invariant sites was selected as the best-fitting model. Maximum likelihood inferences were performed with IQ-TREE, and statistical supports were drawn from 1,000 ultrafast bootstrap values with a 0.99 minimum correlation as convergence criterion ${ }^{43}$, and 1,000 replicates of the SHlike approximate likelihood ratio test ${ }^{44}$.

Pipsqueak Domain Similarity Analysis. A semi-automated BLAST and HMM-based search was conducted with the online Pfam database ${ }^{45}$ and the Pfam HMM profile for pipsqueak domain. E93 sequences of $D$. melanogaster (NP_652002.2), Tribolium castaneum (KYB25179.1), B. germanica (CCM97102.1), Bombyx mori (AIL29268.1), Apis mellifera (BAB64310.1) and Zootermopsis nevadensis (KDR22086.1), Caenorhabditis elegans (AB236333.1) and Homo sapiens (AAH53359.1) were obtained from GenBank database, were used for the analysis.

Quantitative real-time reverse transcriptase polymerase chain reaction (qRT-PCR). Total RNA from individual X. vesparum specimens was extracted using the GenEluteTM Mammalian Total RNA kit (Sigma). cDNA synthesis was carried out as previously described ${ }^{46,47}$. Relative transcript levels were determined by quantitative real-time PCR (qPCR), using Power SYBR Green PCR Mastermix (Applied Biosystems). To standardize the quantitative real-time RT-PCR (qPCR) inputs, a master mix that contained Power SYBR Green PCR Mastermix and forward and reverse primers was prepared to a final concentration of $100 \mu \mathrm{M}$ for each primer. The qPCR experiments were conducted with the same quantity of tissue equivalent input for all treatments, and each sample was run in duplicate using $2 \mu \mathrm{l}$ of cDNA per reaction. As a reference, same cDNAs were subjected to qRT-PCR with a primer pair specific for $X$. vesparum Ribosomal $18 \mathrm{~S}^{36}$. All the samples were analyzed on the iCycler iQReal Time PCR Detection System (Bio-Rad). Primer sequences used for qPCR for $X$ vesparum are:

XvE93-F: 5'-GGTACAACGCGGTGAAATGTC-3'

XvE93-R: 5'-GTTTTCGTGGCCGCATTAAATGC-3'

XvKrhl-F: 5'-TATGCGACGATGTACGCTTA-3'

XvKrh1-R: 5'-CTTGCACGTTTAACACGTCAT-3'

XvHR3-F: 5'-CTACGAGCAAACACCATCGA-3'

XvHR3-R: 5'-GGATTGTAATAAGTCGTATACG-3'

XvE75-F: 5'-GAAAGAGGAACCAACAAGTTC-3'

XvE75-R: 5'-CTTACAACCTTCACATGAATGA- $3^{\prime}$

XvBr-C-F: 5'-GCAGCATTACCTCTGCTT-3'

XvBr-C-R: $5^{\prime}$-CGAAAATATGGGCTGCAG- $3^{\prime}$

Xv18S-F: 5'-TGCGGCGTATCTTTCAATTGT-3'

Xv18S-R: 5'-CTGCCTTCCTTAGATGTGGT-3'.

\section{Results and Discussion}

Identification and phylogenetic analysis of XvE93. X. vesparum E93 (XvE93) full-length sequence was obtained by the assembly of $X$. vesparum transcriptomes from $4^{\text {th }}$ instar female larvae and neotenic females (GenBank accession number MH220841). A single cDNA that corresponds to a transcription factor of 1083 amino acid was identified (Fig. 2A and Supplementary Fig. 1). The comparison with other E93 sequences (Fig. 2B,C), revealed that XvE93 possess two helix-turn-helix (HTH) DNA binding motifs of the pipsqueak family, termed RHF1 and RHF2 (Fig. 2A,B). RHF-1 presents $91-98 \%$ similarity compared to other insects and a $67 \%$ compared to the Caenorhabditis elegans homolog MBR-1, while RHF-2 presents $93-100 \%$ similarity compared to other insects, 71\% compared to MBR-1 and 53\% compared to the human homolog Ligand Co-Repressor (LCoR). Although D. melanogaster DmE93 and human LCoR have only the RHF-2 domain, the two RHF DNA-binding motifs have been shown to be critical for proper induction of $20 \mathrm{E}$ dependent genes in the lepidepteran $B$. mori $i^{48}$, suggesting that both domains, RHF-1 and RHF-2, are required for binding to DNA.

An interesting feature of all E93 homologs is the presence of at least one nuclear receptor interaction motif (NR-box; also named as LXXLL motif). Interestingly, XvE93 contains two of such motifs (Fig. 2A,B). Through these motifs LCoR interacts with different hormone-bound nuclear receptors attenuating their transcriptional activity $^{49,50}$. Likewise, B. mori BmE93 interacts through the NR-box with ultraspiracle (USP), a nuclear receptor that dimerizes with the ecdysone receptor $(\mathrm{EcR})$ to act as the functional $20 \mathrm{E}$ receptor, to impair the transcriptional activity of the heterodimer ${ }^{48}$. Finally, a third conserved domain present in XvE93 is the co-repressor C-terminal-binding protein interaction motif (CtBP-im) (Fig. 2A,B). Overall, the highly conserved protein structure observed in all E93 homologs, including that of X. vesparum, suggests that XvE93 functions through similar molecular mechanisms.

On the other hand, maximum-likelihood analysis of E93 sequences, using the sequences of arachnids E93 as outgroup, showed that XvE93 sequence grouped with those of coleopteran species, which is consistent with phylogenomic inferences ${ }^{2,51}$ (Fig. 3). A remarkable feature of the tree was the different length of the branches. Diptera, and specially flies, had the longest lengths, clearly indicating a faster rate of divergence of these sequences with respect to other insect sequences, whereas non-dipteran branches were shorter, indicating a higher conservation of these sequences.

Differential expression of $X v E 93$ in males and females of $X$. vesparum. As a first step towards the characterization of $E 93$ in neoteny, we measured the expression levels of $X v E 93$ in the larva-to-adult transition of $X$. vesparum. Males of $X$. vesparum progress through four larval stages (one free-living planidium stage and three endoparasitic stages) before undergoing endoparasitic pupation, when the metamorphic transition results in the formation of free-living winged adults (Fig. 1). In contrast, X. vesparum females pass through four larval molts 
A

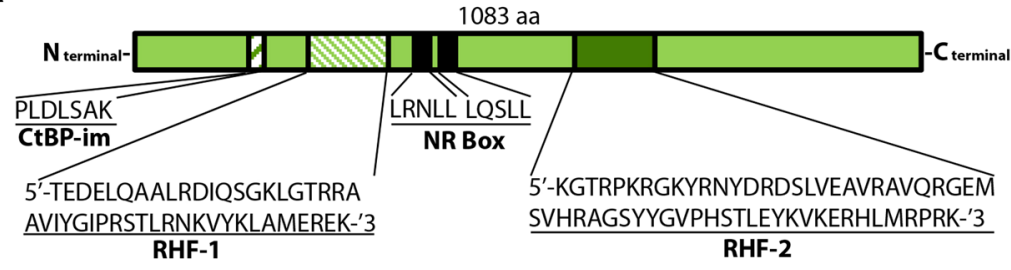

B

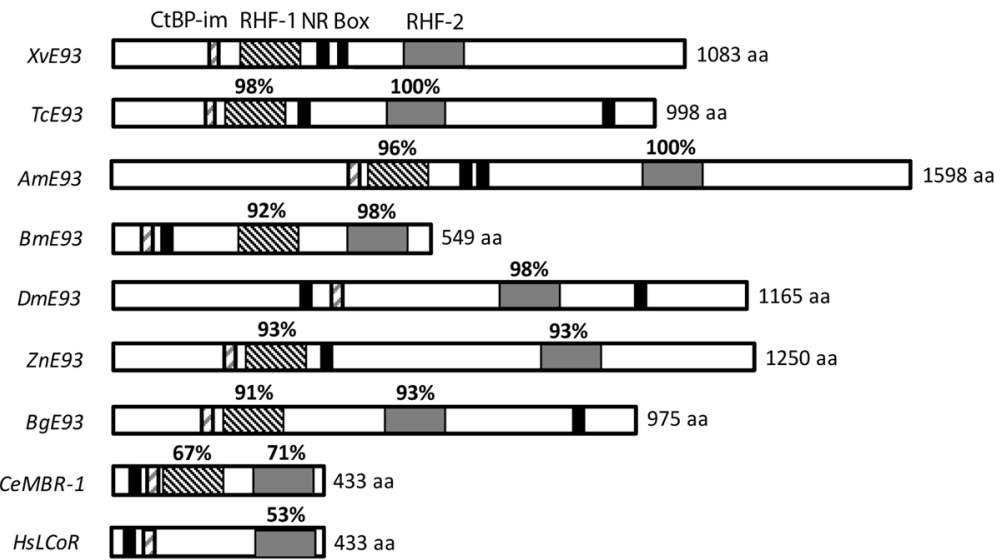

C

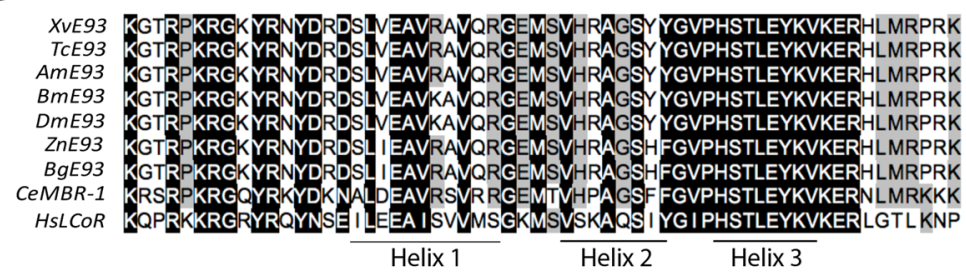

Figure 2. The structure of Xenos vesparum XvE93. (A) Predicted amino acid sequence of XvE93. The two HTH-DNA binding motifs, RHF1 (grey box) and RHF2 (stripped box), are indicated. The two NR-box are boxed in black. The CtBP-interaction motif (CtBP-im) is single-line stripped boxed. (B) Comparison of the domain structure of E93 homologs. Tribolium castaneum (TmE93), Apis mellifera (AmE93), Bombyx mori (BmE93), Drosophila melanogaster (DmE93), Zootermopsis nevadensis (ZnE93), Blattella germanica (BgE93), Caenorhabditis elegans (CeE93) and Homo sapiens (HsLCoR). The percentages indicate the sequence identities within each domain. (C) Comparison of the RHF2 domain of XvE93 with those from other E93 homologs. Amino acid residues highly conserved in E93 insects, MBR-1 from C. elegans and human LCoR are indicated by a reverse background, whereas moderate conserved residues are shaded in grey. The positions of the three helices are indicated by horizontal bars.

(one free-living planidium stage and three endoparasitic stages) which then transform directly into endoparasitic larviform neotenic animals without transiting through the metamorphic-pupal stage (Fig. 1). As shown in Fig. 4A, mRNA expression levels of $X v E 93$ in males were low in $4^{\text {th }}$ larval instar but significantly increased in the pupal and adult stages. In contrast, $X v E 93$ levels in females were very low in $4^{\text {th }}$ instar larvae and did not show any detectable increase in neotenic adults (Fig. 4A).

To characterize in more detail the expression pattern of XvE93 in X. vesparum females, we next measured $X v E 93$ mRNA levels in staged $3^{\text {rd }}$, early and late $4^{\text {th }}$ instar larvae as well as in neotenic female adults. As expected, mRNA expression levels of $X v E 93$ were very low in $3^{\text {rd }}$ and at the beginning of the $4^{\text {th }}$ larval instars, but, surprisingly, the levels of $X v E 93$ were significantly up-regulated at the final part of the $4^{\text {th }}$ larval instar and the adult stage (Fig. 4B). This stage-specific up-regulation of $X v E 93$ is surprising in that, as previously stated, neotenic $X$. vesparum adult females are characterized for the lack of complete metamorphosis and the retention of an overall juvenile morphology. However, the female cephalothorax presents some adult-specific features (Fig. 5A), such as the pheromone glands and structures that support insemination and the release of the $1^{\text {st }}$ instar planidia. This observation raised the possibility that the late increase in $X v E 93$ levels would be related with the development of such structures. To test this hypothesis, we measured the transcript levels of $X v E 93$ separately in cephalothorax and abdomen of the late last juvenile instar, when $X v E 93$ was up-regulated (Fig. 4B), and the neotenic-adult stage. Remarkably, as shown in Fig. 5B, XvE93 was significantly up-regulated in the cephalothorax of $4^{\text {th }}$ instar larvae and neotenic females but not in the abdominal part. This confirms the correlation between the specific increase in 


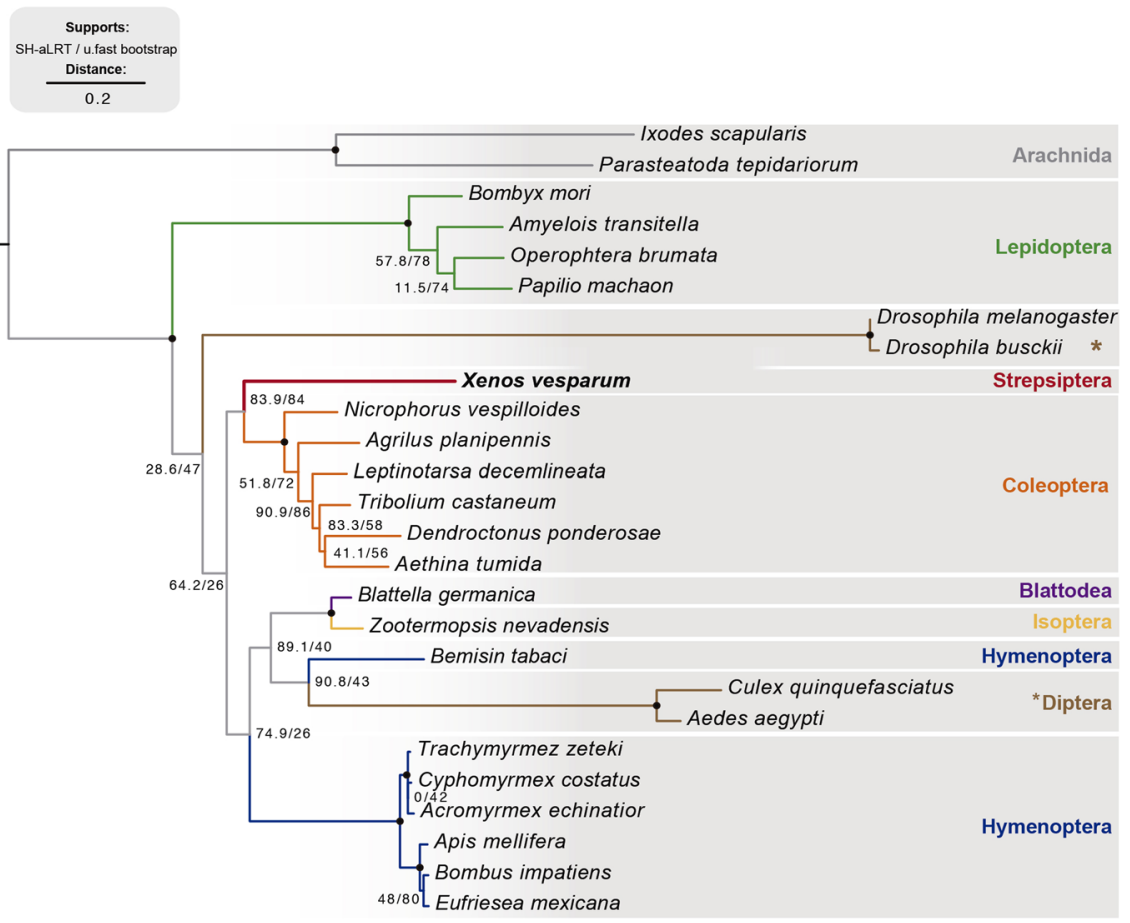

Figure 3. Phylogenetic analysis of E93 proteins. Phylogenetic tree based in protein sequences of E93 from 24 different insect taxa including the E93 sequence of Xenos vesparum described in this study. Two Arachnida E93 sequences are used as outgroup. Branch colors at the tip of the tree indicated the order of the different species used in this analysis. X. vesparum is highlighted in bold.

A

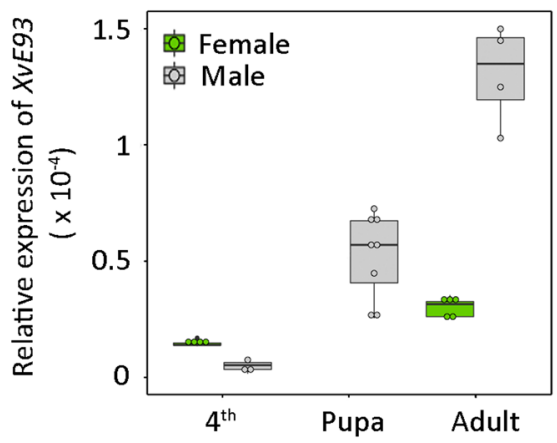

B

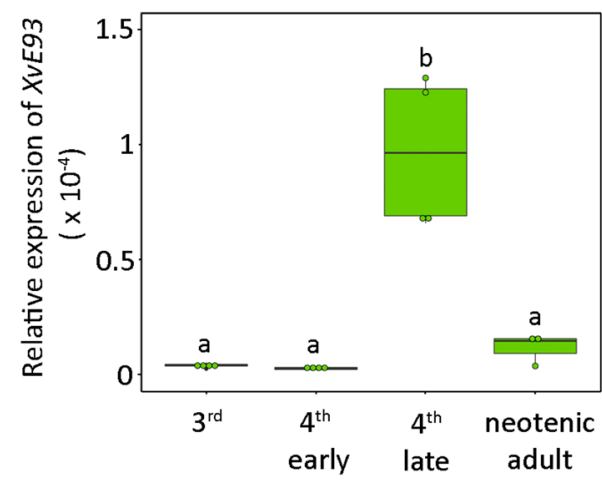

Figure 4. Developmental expression profiles of Xenos vesparum XvE93 in the transition from larvae to adults. (A) XvE93 mRNA levels were measured by qRT-PCR in the larva-to-adult transition in male ( $4^{\text {th }}$, pupa, adult) and female ( $4^{\text {th }}$ and adult) whole bodies. (B) XvE93 mRNA levels (qRT-PCR) in the whole body of $3^{\text {th }}$, early and late $4^{\text {th }}$ and neotenic females. Transcript abundance values in panels A and B are normalized against the $X v$ Ribosomal $18 S$ transcript. The range of expression is shown by Boxplot: boxes demarcate the upper and lower quartiles, while the heavy bar indicates the median value of normalized expression. Whiskers extend to the most extreme values. Points represent each individual measurement. Different letters in panel B represent groups with significant differences according to ANOVA test (Tukey, $\mathrm{p} \leq 0.005$ ).

$X v E 93$ expression in the cephalothorax with the occurrence of adult-specific structures in this part of the neotenic female.

Next, we investigated how the expression of $X v E 93$ is differentially regulated in neotenic females. Since E93 expression is induced by $20 \mathrm{E}$ in holometabolous insects ${ }^{35,48,52,53}$, the differential expression could be explained by differences in the signaling, or response to $20 \mathrm{E}$ in different parts of $X$. vesparum female body. To test this, we analyzed the differential expression of XvHR3 and XvE75 (GenBank accession numbers MH220843 and MH220844, respectively), two 20E-dependent nuclear receptors of the stereotypic genetic cascade that responds to the $20 \mathrm{E}$ signal in insects ${ }^{47,54}$. Remarkably, the mRNA levels of both factors were higher in the cephalothorax of female $4^{\text {th }}$ instar larvae compared to the abdominal region (Fig. 5C,D). Higher levels of $X v H R 3$ and $X v E 75$ remained in the 
A

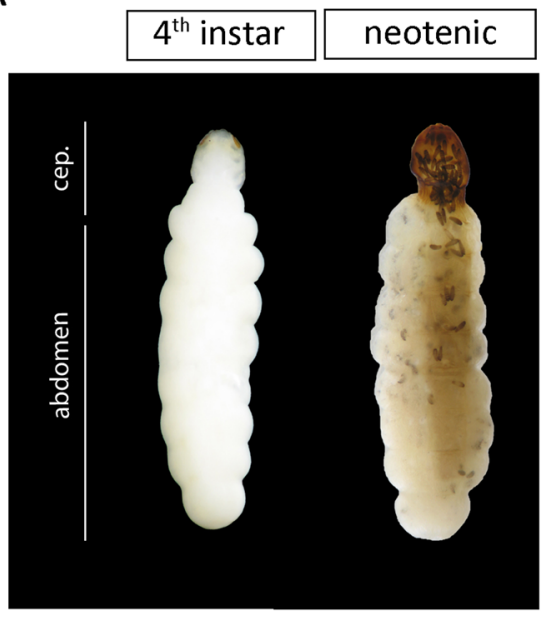

B

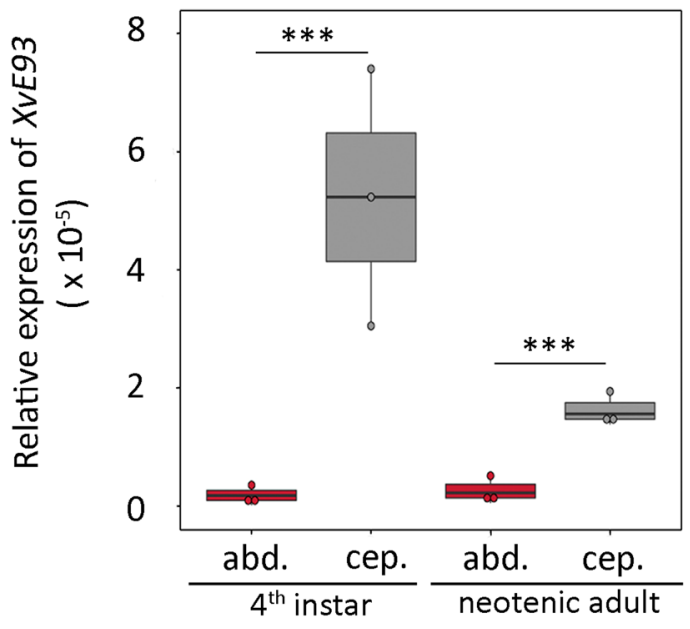

C

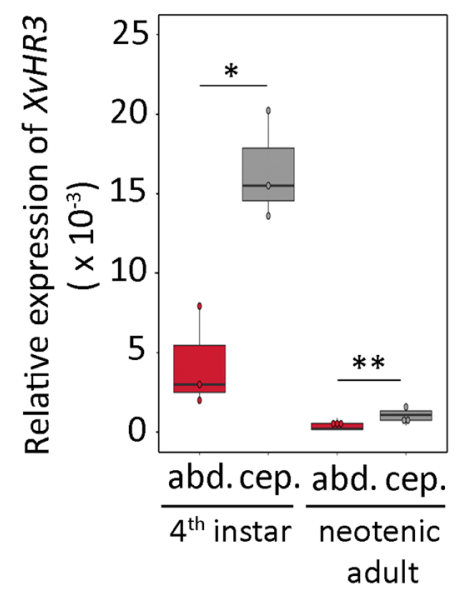

D

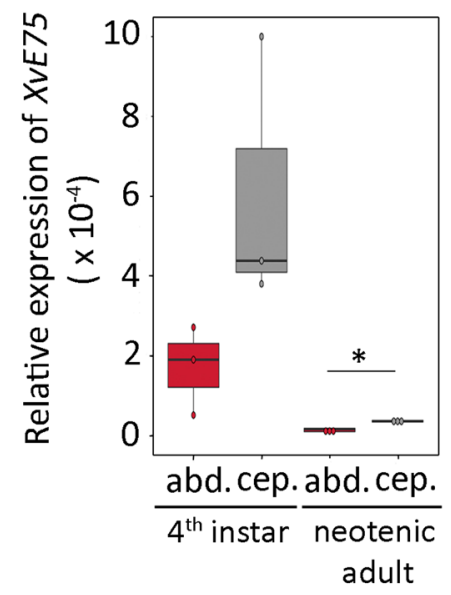

$\mathrm{E}$

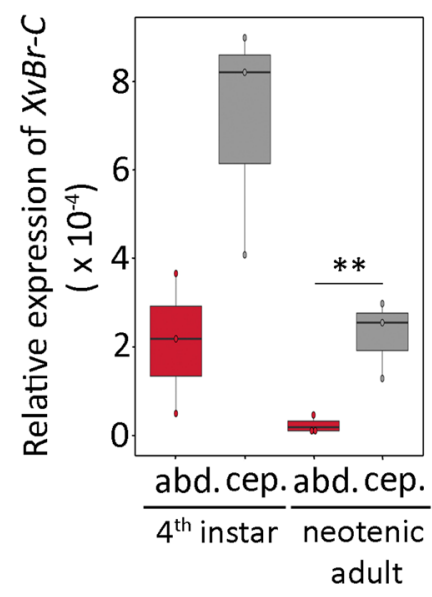

Figure 5. Expression levels of $X v E 93, X v H R 3, X v E 75$, and $X v B r-C$ in the cephalothorax and abdomen of Xenos vesparum females. (A) Dorsal views of a $4^{\text {th }}$ instar larva and a neotenic adult female. The abdomen (abd.) and the cephalothorax (cep.) regions are marked. (B-E) Transcript levels of (B) XvE93, (C) XvHR3, (D) XvE75, and (E) $\mathrm{XvBr}$-C (without discriminating isoforms) were measured by qRT-PCR in the cephalothorax and abdomen of $4^{\text {th }}$ instar larvae and neotenic adult females. Transcript abundance values in panels B-E are normalized against the XvRibosomal $18 S$ transcript. The range of expression is shown by Boxplot: boxes demarcate the upper and lower quartiles, while the heavy bar indicates the median value of normalized expression. Whiskers extend to the most extreme values. Points represent each individual measurement. Asterisks indicate differences statistically significant at $* \mathrm{p} \leq 0.05 ; * \mathrm{p} \leq 0.01$; and $* * * \mathrm{p} \leq 0.001$ ( $t$-test $)$.

cephalothorax of neotenic females, although the levels of both factors were very low (Fig. 5C,D). Overall, these results suggest that higher levels of $20 \mathrm{E}$ signaling in the cephalothorax of last instar X. vesparum female larvae could be responsible for the particular increase in the expression of $X v E 93$ in this region, which, in turn, results in the "metamorphic" transformation of the anterior part of the body.

In all holometabolous insects studied to date, E93 is highly expressed specifically during the pupal and adult stages $1,34,35,48,53$. Functional studies have shown that E93 is required during the pupal period for proper adult differentiation, as RNA interference (RNAi)-mediated depletion of E93 prevented pupal-adult transition in $D$. melanogaster or even produced a supernumerary second pupa in T. castaneum $^{1,34}$. Similar results were also observed in the lepidopteran B. mori ${ }^{48}$. Remarkably, the function of E93 is conserved in hemimetabolous insects ${ }^{34,55}$. In the hemimetabolous cockroach B. germanica, BgE93 is highly expressed in metamorphic tissues during the last nymphal instar, and RNAi-mediated knockdown of $B g E 93$ in the nymphal stage prevented the nymphal-adult transition, inducing endless reiteration of nymphal stages ${ }^{34}$. Due to the evolutionary conservation of its expression and function, E93 is considered the "master factor" of adult metamorphosis in winged insects ${ }^{34}$. Importantly, the expression dynamic of $X v E 93$ in $X$. vesparum males reported in our work is consistent with the expression of E93 in all holometabolous insects analyzed to date. In addition to the expression pattern of $X v E 93$ in males, it has been previously suggested that the expression of the pupal-specifier $X v B r$-C presents a consistent increase during $4^{\text {th }}$ larval instar and early pupa stages in $X$. vesparum males ${ }^{36}$, an expression pattern that is consistent with that 
A

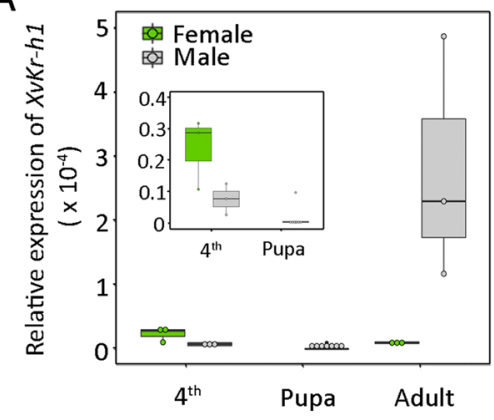

B

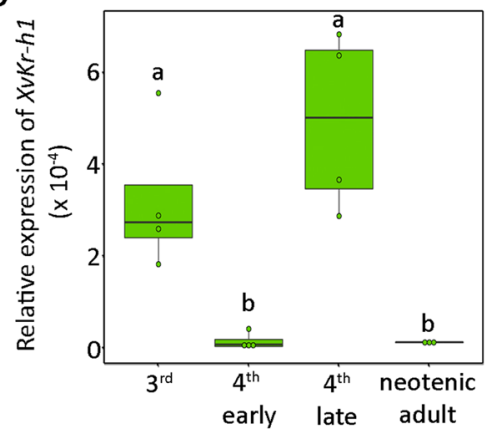

$\mathrm{C}$

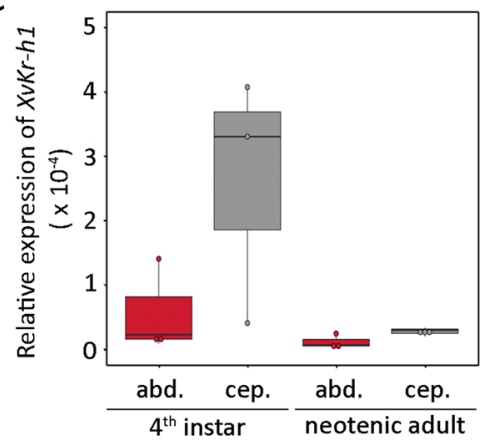

Figure 6. Developmental expression profiles of Xenos vesparum $X v K r-h 1$ in the larva to adult transition. (A) $X v K r$ - $h 1$ mRNA levels were measured by qRT-PCR in the larva-to-adult transition in male ( $4^{\text {th }}$, pupa, adult) and female ( $4^{\text {th }}$ and adult) whole bodies. The inset panel shows a magnification of expression levels in $4^{\text {th }}$ larval instar and pupa. (B) $X v K r-h 1$ mRNA levels (qRT-PCR) in the whole body of $3^{\text {th }}$, early and late $4^{\text {th }}$ and neotenic females. (C) $X v K r$ - $h 1$ mRNA levels (qRT-PCR) in the cephalothorax (cep.) and abdomen (abd.) of $4^{\text {th }}$ instar larvae and neotenic adult females. Transcript abundance values in all panels are normalized against the XvRibosomal $18 S$ transcript. The range of expression is shown by Boxplot: boxes demarcate the upper and lower quartiles, while the heavy bar indicates the median value of normalized expression. Whiskers extend to the most extreme values. Points represent each individual measurement. Different letters in panel B represent groups with significant differences according to ANOVA test (Tukey, $\mathrm{p} \leq 0.005$ ). Asterisks in panel C indicate differences statistically significant at $* * \mathrm{p} \leq 0.01$ ( $t$-test).

observed in other holometabolous insects ${ }^{28,29,32,56,57}$. Altogether, these data show that male $X$. vesparum displays the typical holometabolous metamorphic development characterized by the sequential occurrence of Br- $\mathrm{C}$ during the larval-pupal transition and of E93 during the pupal-adult transition. In contrast, in females we observed very low levels of $X v E 93$ in the $4^{\text {th }}$ instar larvae and in neotenic females. Likewise, the expression of $X v B r-C$ in females does not show a detectable induction in the same developmental period ${ }^{36}$. The absence in neotenic females of the typical holometabolous expression pulses of $X v E 93$ (this paper) and $\mathrm{XvBr}$ - $\mathrm{C}^{36}$ during the larval-to-adult transition correlates with the lack of the pupal stage, and clearly suggests that the suppression of the pupal determination program has contributed to the occurrence of female neoteny in X. vesparum.

It is interesting to note, however, that although $X$. vesparum neotenic females retain an overall larviform appearance at the posterior part of the body, the anterior extruded part of the body, the cephalothorax, undergoes a "metamorphic-like" transformation between the $4^{\text {th }}$ larval instar and the adult stages without an intermediate pupal stage. This transformation includes the development of structures to aid insemination, the release of the planidia as well as the pheromone glands ${ }^{20}$. Remarkably, we have found that the occurrence of such "metamorphic-like" process in the cephalothorax correlates with the significant increase of XvE93, XvHR3 and $X v E 75$ expression in this part of the body (Fig. 5). Interestingly, we observed that $\mathrm{XvBr}$ - $\mathrm{C}$ was also up-regulated in the cephalothorax of $4^{\text {th }}$ instar larvae and neotenic females compared to the abdominal part (Fig. 5E), suggesting that a differential increase in 20E signaling in the cephalothorax results in higher expression levels of $X v E 93$ and $X v B r-C$, which controls the development of adult features. Altogether, our results show that the suppression of $X v E 93$ and $X v B r-C$ expression in $X$. vesparum females, especially in the abdominal part of the body, may underlie the development of female neoteny in Strepsiptera.

A change in the expression of key developmental genes seems to be also underlying the evolution of progenesis, a second developmental strategy of paedogenesis that consists in the early growth and maturation of the ovaries during larval development. In the dipterans Heterozepa pygmaea and Mycophila speyeri, for example, a precocious up-regulation of the heterodimer EcR/USP in the ovaries of first instar larvae correlates with the early maturation of the ovary within the larval body in paedogeneic females ${ }^{58}$. Therefore, critical variations in the expression levels of genes that are important for the transduction of $\mathrm{JH}$ and $20 \mathrm{E}$ hormonal signaling may be responsible for the occurrence of paedogenesis in insects.

Expression of $X v K r$ - $h 1$ during metamorphic and neotenic development in $X$. vesparum. Finally, to characterize the expression of the genes that form the MGN, we identified the transcription factor $X v K r-h 1$ in this species. To this aim, we isolated a fragment that encompasses seven zing-fingers of the DNA-binding domain through the assembling of X. vesparum transcriptomes (GenBank accession number MH220842) (Supplementary Fig. 2). We, then, analyzed the expression of $X v K r-h 1$ during the larval-adult transition in $X$. vesparum. In males, $X v K r-h 1$ mRNA levels were low in $4^{\text {th }}$ instar larvae, almost undetectable in the pupal period, and significantly high in the adult (Fig. 6A). In contrast, consistent with the absence of pupal stage in the neotenic female, $X v K r$ - $h 1$ mRNA levels did not show differences between $4^{\text {th }}$ instar larva and the neotenic female (Fig. 6A). As before, we next analyzed in detail the expression levels of $X v K r-h 1$ in females and found that $X v K r-h 1$ was clearly detected in $3^{\text {rd }}$ instar larvae, but its levels significantly dropped at the onset of the $4^{\text {th }}$ larval instar, only to reappear at the final part of the instar (Fig. 6B). In the neotenic adult female, low levels of $X v K r$ - $h 1$ were detected (Fig. 6B). Interestingly, although not significant, the increase in $X v K r-h 1$ expression in late $4^{\text {th }}$ larval instar was higher in 
the cephalothorax compared to the abdominal region, while in neotenic animals very low levels of $X v K r$ - $h 1$ were detected in both parts of the body (Fig. 6C).

Similar to XvE93, the expression pattern of $\mathrm{XvKr}$ - $h 1$ in the male is comparable to those observed in holometabolous insects, in which $K r$ - $h 1$ is expressed through larval development to become strongly repressed by E93 during the pupal stage, and to reappear during the adult stage ${ }^{1,26,27,59}$. On the other hand, the levels of $X v K r-h 1$ in females display a particular dynamic: at the early last larval stage, the decline of $X v K r-h 1$ is similar to that observed at the onset of the last larval instar of holometabolous insects; however, at the final part of the $4^{\text {th }}$ instar, $X v K r-h 1$ is up-regulated in the cephalothorax region in parallel to the increase in the expression of $X v E 93$ and $\mathrm{XvBr}$-C. This result suggests that in the neotenic female, $\mathrm{XvKr}-\mathrm{h} 1 \mathrm{~h}$ has lost the strong repressive activity upon $X v E 93$ and $X v B r$-C expression that is observed in holometabolous insects studied ${ }^{1,35}$. Alternatively, it is plausible that the up-regulation of $X v K r-h 1$ in $4^{\text {th }}$ instar larva is necessary to prevent a stronger transcriptional induction of $X v E 93$ that would result in the activation of the adult genetic program in the body of female X. vesparum.

\section{Concluding Remarks}

Loss of complete metamorphosis in the strepsipteran suborder Stylopidia has evolved exclusively in females. Males, however, display the typical holometabolous larva-pupa-adult transition. Correlating with the presence of the metamorphic pupal stage in $X$. vesparum males, high levels of expression of the adult specifier $X v E 93$, along with the disappearance of the anti-metamorphic $X v K r-h 1$, are detected in the pupal stage. In contrast, very low levels of $X v E 93$ are observed throughout development of $X$. vesparum females. However, a specific up-regulation of $X v E 93$ and $X v B r-C$ in the cephalothorax of late female $4^{\text {th }}$ instar larva correlates with the occurrence of adult-specific features in the anterior part of the neotenic female body. Overall, our results, together with previous work ${ }^{36}$, suggest that neoteny in strepsipteran females arose by the suppression of the genetic program that controls the formation of the pupa, that is the sequential expression of $X v B r-C$ and $X v E 93$ factors at the end of larval development. The loss of expression of $X v E 93$ and $X v B r-C$ in $X$. vesparum females could be the result of changes in the endocrine milleu, with alterations in the titer of $\mathrm{JH}$ and/or 20E in particular stages of development. There might also be changes in the regulation of the expression of these genes, as suggest by the fact that XvKr-h1 does not seem to act as a potent repressor of $X v E 93$ and $X v B r-C$ in females. In summary, our work highlights the importance of the MGN in the regulation of insect metamorphosis and in the evolution of insect neoteny in the order Strepsiptera.

\section{References}

1. Ureña, E., Chafino, S., Manjón, C., Franch-Marro, X. \& Martín, D. The Occurrence of the Holometabolous Pupal Stage Requires the Interaction between E93, Krüppel-Homolog 1 and Broad-Complex. PLoS Genet 12, e1006020-24 (2016).

2. Misof, B. et al. Phylogenomics resolves the timing and pattern of insect evolution. Science 346, 763-767 (2014).

3. Sehnal, F., Švácha, P. \& Zrzavý, J. In Metamorphosis 3-58, https://doi.org/10.1016/B978-012283245-1/50003-8 (Elsevier, 1996).

4. Grimaldi, D. \& Engel, M. S. Evolution of the Insects. (Cambridge University Press, 2005).

5. Nicholson, D. B., Ross, A. J. \& Mayhew, P. J. Fossil evidence for key innovations in the evolution of insect diversity. Proc. Biol. Sci. 281, 20141823-20141823 (2014).

6. Rainford, J. L., Hofreiter, M., Nicholson, D. B. \& Mayhew, P. J. Phylogenetic distribution of extant richness suggests metamorphosis is a key innovation driving diversification in insects. PLOS ONE 9, e109085 (2014).

7. Gould, S. J. Ontogeny and Phylogeny. (Belzap Press, 1977).

8. Bergstrom, C. T. \& Dugatkin, L. A. Evolution. (2011).

9. Bocak, L., Bocakova, M., Hunt, T. \& Vogler, A. P. Multiple ancient origins of neoteny in Lycidae(Coleoptera): consequences for ecology and macroevolution. Proc. Biol. Sci. 275, 2015-2023 (2008).

10. Kundrata, R. \& Bocak, L. The phylogeny and limits of Elateridae (Insecta, Coleoptera): is there a common tendency of click beetles to soft-bodiedness and neoteny? Zoologica Scripta 40, 364-378 (2011).

11. Kinzelbach, R. Redescription and revision of the Strepsiptera genus Hylecthrus Saunders, 1850. Angew Parasitol 12, 204-220 (1971).

12. Kathirithamby, J. Review of the Order Strepsiptera. Systematic Entomology 14, 41-92 (1989).

13. Kathirithamby, J. Host-parasitoid associations in Strepsiptera. Annual Review of Entomology 54, 227-249 (2009).

14. Butler, M. J. et al. Discovery of genes with highly restricted expression patterns in the Drosophila wing disc using DNA oligonucleotide microarrays. Development 130, 659-670 (2003).

15. Kathirithamby, J. In Insect Biodiversity (John Wiley \& Sons, 2018).

16. Hrabar, M., Danci, A., McCann, S., Schaefer, P. W. \& Gries, G. New findings on life history traits of Xenos peckii (Strepsiptera: Xenidae). The Canadian Entomologist 146, 514-527 (2014).

17. Cvačka, J. et al. Stylopsal: the first identified female-produced sex pheromone of strepsiptera. J. Chem. Ecol. 38, 1483-1491 (2012).

18. Tolasch, T., Kehl, S., Ecology, S. D. J. O. C.2012. First Sex Pheromone of the Order Strepsiptera: (3R,5R,9R)-3,5,9Trimethyldodecanal in Stylops melittae Kirby, 1802. J. Chem. Ecol. https://doi.org/10.1007/s10886-012-0214-7

19. Hrabar, M. et al. (7E,11E)-3,5,9,11-Tetramethyltridecadienal: Sex Pheromone of the Strepsipteran Xenos peckii. J. Chem. Ecol. 41, 732-739 (2015)

20. Kathirithamby, J. et al. We do not select, nor are we choosy: reproductive biology of Strepsiptera (Insecta). Biological Journal of the Linnean Society 116, 221-238 (2015).

21. Truman, J. W. \& Riddiford, L. M. Endocrine insights into the evolution of metamorphosis in insects. Annual Review of Entomology 47, 467-500 (2002).

22. Truman, J. W. \& Riddiford, L. M. The morphostatic actions of juvenile hormone. Insect Biochem Mol Biol 37, 761-770 (2007).

23. Jindra, M., Palli, S. R. \& Riddiford, L. M. The Juvenile Hormone Signaling Pathway in Insect Development. Annual Review of Entomology 58, 181-204 (2013).

24. Hiruma, K. \& Kaneko, Y. Hormonal regulation of insect metamorphosis with special reference to juvenile hormone biosynthesis. Curr Top Dev Biol 103, 73-100 (2013).

25. Yamanaka, N., Rewitz, K. F. \& O'Connor, M. B. Ecdysone Control of Developmental Transitions: Lessons from Drosophila. Research. 58, 497-516 (2012).

26. Minakuchi, C., Namiki, T. \& Shinoda, T. Krüppel homolog 1, an early juvenile hormone-response gene downstream of Methoprenetolerant, mediates its anti-metamorphic action in the red flour beetle Tribolium castaneum. Dev Biol 325, 341-350 (2009).

27. Kayukawa, T. et al. Hormonal regulation and developmental role of Krüppel homolog 1, a repressor of metamorphosis, in the silkworm Bombyx mori. Dev Biol 388, 48-56 (2014). 
28. Suzuki, Y., Truman, J. W. \& Riddiford, L. M. The role of Broad in the development of Tribolium castaneum: implications for the evolution of the holometabolous insect pupa. Development 135, 569-577 (2008).

29. Konopova, B. \& Jindra, M. Broad-Complex acts downstream of Met in juvenile hormone signaling to coordinate primitive holometabolan metamorphosis. Development 135, 559-568 (2008).

30. Parthasarathy, R., Tan, A., Bai, H. \& Palli, S. R. Transcription factor broad suppresses precocious development of adult structures during larval-pupal metamorphosis in the red flour beetle, Tribolium castaneum. Mech Dev 125, 299-313 (2008).

31. Uhlirova, M. et al. Use of Sindbis virus-mediated RNA interference to demonstrate a conserved role of Broad-Complex in insect metamorphosis. Proc Natl Acad Sci USA 100, 15607-15612 (2003).

32. Zhou, X. \& Riddiford, L. M. Broad specifies pupal development and mediates the 'status quo'action of juvenile hormone on the pupal-adult transformation in Drosophila and Manduca. Development 129, 2259-2269 (2002).

33. Kayukawa, T. et al. Krüppel Homolog 1 Inhibits Insect Metamorphosis via Direct Transcriptional Repression of Broad-Complex, a Pupal Specifier Gene. The Journal of biological chemistry 291, 1751-1762 (2016).

34. Ureña, E., Manjón, C., Franch-Marro, X. \& Martín, D. Transcription factor E93 specifies adult metamorphosis in hemimetabolous and holometabolous insects. Proc Natl Acad Sci USA 111, 7024-7029 (2014).

35. Kayukawa, T., Jouraku, A., Ito, Y. \& Shinoda, T. Molecular mechanism underlying juvenile hormone-mediated repression of precocious larval-adult metamorphosis. Proc Natl Acad Sci USA 114, 1057-1062 (2017).

36. Erezyilmaz, D. F. et al. Expression of the pupal determinant broad during metamorphic and neotenic development of the strepsipteran Xenos vesparum Rossi. PLoS ONE 9, e93614 (2014).

37. Bankevich, A. et al. SPAdes: A New Genome Assembly Algorithm and Its Applications to Single-Cell Sequencing. Journal of Computational Biology 19, 455-477 (2012).

38. Bolger, A. M., Lohse, M. \& Usadel, B. Trimmomatic: a flexible trimmer for Illumina sequence data. Bioinformatics 30, 2114-2120 (2014).

39. Camacho, C. et al. BLAST+: architecture and applications. BMC Bioinformatics 10, 421 (2009).

40. Katoh, K. \& Standley, D. M. MAFFT Multiple Sequence Alignment Software Version 7: Improvements in Performance and Usability. Molecular biology and evolution 30, 772-780 (2013).

41. Capella-Gutierrez, S., Silla-Martinez, J. M. \& Gabaldon, T. trimAl: a tool for automated alignment trimming in large-scale phylogenetic analyses. Bioinformatics 25, 1972-1973 (2009).

42. Nguyen, L.-T., Schmidt, H. A., Haeseler, von, A. \& Minh, B. Q. IQ-TREE: a fast and effective stochastic algorithm for estimating maximum-likelihood phylogenies. Molecular biology and evolution 32, 268-274 (2015).

43. Minh, B. Q., Nguyen, M. A. T. \& Haeseler von, A. Ultrafast Approximation for Phylogenetic Bootstrap. Molecular biology and evolution 30, 1188-1195 (2013).

44. Guindon, S. et al. New algorithms and methods to estimate maximum-likelihood phylogenies: assessing the performance of PhyML 3.0. Syst. Biol. 59, 307-321 (2010).

45. Finn, R. D. et al. The Pfam protein families database: towards a more sustainable future. Nucleic Acids Res. 44, D279-85 (2016).

46. Cruz, J. et al. Quantity does matter. Juvenile hormone and the onset of vitellogenesis in the German cockroach. Insect Biochem Mol Biol 33, 1219-1225 (2003).

47. Mané-Padrós, D. et al. The hormonal pathway controlling cell death during metamorphosis in a hemimetabolous insect. Dev Biol 346, 150-160 (2010).

48. Liu, X. et al. 20-Hydroxyecdysone (20E) Primary Response Gene E93 Modulates 20E Signaling to Promote Bombyx Larval-Pupal Metamorphosis. The Journal of biological chemistry 290, 27370-27383 (2015).

49. Fernandes, I. et al. Ligand-dependent nuclear receptor corepressor LCoR functions by histone deacetylase-dependent and -independent mechanisms. Mol Cell 11, 139-150 (2003).

50. Takayanagi-Kiya, S., Kiya, T., Kunieda, T. \& Kubo, T. Mblk-1 Transcription Factor Family: Its Roles in Various Animals and Regulation by NOL4 Splice Variants in Mammals. Int J Mol Sci 18, 246 (2017).

51. Boussau, B. et al. Strepsiptera, Phylogenomics and the Long Branch Attraction Problem. PLoS ONE 9, e107709 (2014).

52. Baehrecke, E. H. \& Thummel, C. S. The Drosophila E93 gene from the $93 \mathrm{~F}$ early puff displays stage- and tissue-specific regulation by 20-hydroxyecdysone. Dev Biol 171, 85-97 (1995).

53. Mou, X., Duncan, D. M., Baehrecke, E. H. \& Duncan, I. Control of target gene specificity during metamorphosis by the steroid response gene E93. Proc Natl Acad Sci USA 109, 2949-2954 (2012).

54. Mané-Padrós, D., Borràs-Castells, F., Bellés, X. \& Martín, D. Nuclear receptor HR4 plays an essential role in the ecdysteroidtriggered gene cascade in the development of the hemimetabolous insect Blattella germanica. Mol. Cell. Endocrinol. 348, 322-330 (2012).

55. Gujar, H. \& Palli, S. R. Krüppel homolog 1 and E93 mediate Juvenile hormone regulation of metamorphosis in the common bed bug, Cimex lectularius. Sci Rep 6, 26092 (2016).

56. Zhou, B., Hiruma, K., Shinoda, T. \& Riddiford, L. M. Juvenile hormone prevents ecdysteroid-induced expression of broad complex RNAs in the epidermis of the tobacco hornworm, Manduca sexta. Dev Biol 203, 233-244 (1998).

57. Ijiro, T., Urakawa, H., Yasukochi, Y., Takeda, M. \& Fujiwara, Y. cDNA cloning, gene structure, and expression of Broad-Complex (BR-C) genes in the silkworm, Bombyx mori. Insect Biochem Mol Biol 34, 963-969 (2004).

58. Hodin, J. \& Riddiford, L. M. Parallel alterations in the timing of ovarian Ecdysone Receptor and Ultraspiracle expression characterize the independent evolution of larval reproduction in two species of gall midges (Diptera: Cecidomyiidae). Dev Genes Evol 210, $358-372(2000)$

59. Minakuchi, C., Zhou, X. \& Riddiford, L. M. Krüppel homolog 1 (Kr-h1) mediates juvenile hormone action during metamorphosis of Drosophila melanogaster. Mech Dev 125, 91-105 (2008).

\section{Acknowledgements}

Support for this research was provided by the Spanish MINECO (grant CGL2014-55786-P to D.M., E.C. and X.F.-M.) and by the Catalan Government (2014 SGR 619 to D.M. and X.F.-M., and 2017 SGR 1030 to D.M, X.F.-M. and E.C.). The research has also benefited from FEDER funds. S.C. is a recipient of a pre-doctoral research Grant from the MINECO. J.K. would like to thank Sebastian Shimeld (Department of Zoology, Oxford) for the help and support in 2017.

\section{Author Contributions}

Conception and design of the project was done by J.K., S.C. and D.M. G.B. and H.K. collected the samples. S.C. performed the experiments. D.L.-E. performed the bioinformatics analysis. The analysis of the data was conducted by S.C., J.K., E.C., X.F.-M. and D.M. S.C. and D.M. wrote the manuscript and J.K., E.C. and X.F.-M. revised the manuscript. All authors approved the final manuscript. 


\section{Additional Information}

Supplementary information accompanies this paper at https://doi.org/10.1038/s41598-018-32611-y.

Competing Interests: The authors declare no competing interests.

Publisher's note: Springer Nature remains neutral with regard to jurisdictional claims in published maps and institutional affiliations.

(c) (1) Open Access This article is licensed under a Creative Commons Attribution 4.0 International License, which permits use, sharing, adaptation, distribution and reproduction in any medium or format, as long as you give appropriate credit to the original author(s) and the source, provide a link to the Creative Commons license, and indicate if changes were made. The images or other third party material in this article are included in the article's Creative Commons license, unless indicated otherwise in a credit line to the material. If material is not included in the article's Creative Commons license and your intended use is not permitted by statutory regulation or exceeds the permitted use, you will need to obtain permission directly from the copyright holder. To view a copy of this license, visit http://creativecommons.org/licenses/by/4.0/.

(C) The Author(s) 2018 